Article

\title{
Towards 100 Positive Energy Districts in Europe: Preliminary Data Analysis of 61 European Cases
}

\author{
Silvia Bossi ${ }^{1, *}$,, Christoph Gollner ${ }^{2}$ and Sarah Theierling ${ }^{2}$ \\ 1 Italian National Agency for Technologies, Energy and Sustainable Economic Development, ENEA, \\ CR Casaccia, 00123 Rome, Italy \\ 2 Austrian Research Promotion Agency, FFG, 1090 Vienna, Austria; Christoph.Gollner@ffg.at (C.G.); \\ sarah.theierling@ffg.at (S.T.) \\ * Correspondence: silvia.bossi@enea.it
}

Received: 12 October 2020; Accepted: 16 November 2020; Published: 20 November 2020

\begin{abstract}
Positive Energy Districts and Neighborhoods (PEDs) are seen as a promising pathway towards sustainable urban areas. Several cities have already taken up such PED-related developments. To support such approaches, European countries joined forces to achieve 100 PEDs until 2025 through a comprehensive research and innovation program. A solid understanding and consideration of cities' strategies, experiences and project features serve as the basis for developing and designing the PED program. JPI Urban Europe has been collecting information on projects towards sustainable urbanization and the energy transition across Europe. The collected cases are summarized in a PED Booklet whose update was recently published on the JPI Urban Europe website. Results presented in this paper provide insights from the analysis of 61 projects in Europe and offer recommendations for future PED developments.
\end{abstract}

Keywords: Positive Energy District (PED); PED Booklet; SET-Plan

\section{Introduction}

Cities have a strong impact on greenhouse gas production and climate change, and several programs and initiatives are focused on new strategies to transform cities into climate neutral ones $[1,2]$.

The Strategic Energy Technology (SET) Plan, adopted by the European Union in 2008 to establish an energy technology strategy in that region, is focused on 10 key action fields, of which Action 3.2 aims to support the planning, deployment and replication of 100 Positive Energy Districts by 2025 for sustainable urbanization [3].

The Program on Positive Energy Districts and Neighborhoods (PED Program) is conducted by JPI Urban Europe in cooperation with the SET Plan Action 3.2, and it involves stakeholders from city administrations, urban planning, industry, research, and civic society organizations [4]. This is seen as an important contribution to current policies on achieving the goals of reducing Europe's carbon footprint, managing the energy transition, and cities' ambitions towards sustainable urban development. A solid understanding and consideration of cities' experiences and strategies serves as the base of developing the program. This is why the PED program aims at a strong involvement of all stakeholder groups in the program's implementation.

A framework for PED has been defined as follows: "Positive Energy Districts are energy-efficient and energy-flexible urban areas or groups of connected buildings which produce net zero greenhouse gas emissions and actively manage an annual local or regional surplus production of renewable energy. They require integration of different systems and infrastructures and interaction between buildings, the users and the regional energy, mobility and ICT systems, while securing the energy supply and a good life for all in line with social, economic and environmental sustainability" [5]. 
The primary energy is the performance indicator of the PED definition and the balance includes both building operations and user-related energy consumptions. Participating PED program partners have agreed that this PED reference framework offers a common baseline across all countries while ensuring flexibility regarding local conditions for PEDs at the same time. Consequently, guidelines for identifying geographical and virtual boundaries of PEDs are still under discussion in collaboration with other programs (i.e., EERA Joint Program Smart Cities) with the ambition of making PEDs achievable for wide range of possible approaches. Examples of PED projects are already under development in Europe in connection with research activities [6-8].

A PED Program mapping of urban projects dealing with the energy transition and sustainability aims to provide an overview of projects, approaches and strategies towards Positive Energy Districts. A compilation of these current cases serves as a basis for knowledge exchange and identification of good practice. The collected cases are summarized in a PED Booklet, an update of which was recently published on the JPI Urban Europe website [9].

Of the 61 cases described in the Booklet, 29 declared a PED ambition. This paper analyses data collected in the PED Booklet to identify common features, strategies, challenges, and success factors of PED projects to guide stakeholders in this field.

For this analysis it must be considered that not all countries have equally contributed to the Booklet yet. The Booklet is based on voluntary contributions from individual PED-related projects and will be continuously updated. Therefore, the results do not allow any interpretation about the level of PED efforts across Europe in general yet.

\section{Materials and Methods}

For this study, the 61 cases described in the PED Booklet (later referred to as Booklet) were considered and analyzed. Project descriptions were collected using a template that was sent out to reference persons of each project. The template was organized into 4 sections:

- General information: this section included information about geographical position, contacts, size, building structure, land use, and financing. Some of these questions allowed multiple choice answers.

- Overview description of the project: this section provided with a text description with the possibility to add further project information and illustrations.

- Strategies: this part included multiple choice questions about goals/ambitions, expected impact, overall strategy of city municipality, factors included in implementation strategies, stakeholder involvement strategies, and typology of energy supply.

- Success factors, challenges, and barriers: text descriptions were collected on key learnings regarding supportive and inhibiting factors in the PED implementation process.

The first question in the "Strategies" section of the template was on goals and ambitions. Among the multiple choices, there was the option "Positive Energy". The cases were divided in two categories: projects that declared a PED ambition (PED, $N_{P}=29$ ) versus projects that did not declare a PED ambition but presented interesting features for the PED Program (Towards (To)-PED, $\mathrm{N}_{T P}=32$ ).

The data were collected in an Excel file table and analyzed separately for PED and To-PED. Only features with less than $30 \%$ of $\mathrm{n} / \mathrm{a}$ data were selected as reliable and worthy to be analyzed:

- Geographic distribution

- Implementation status

- Building structure

- Land use

- Energy typology

- Success factors, challenges, and barriers 


\section{Results}

\subsection{Geographic Distribution of PED and Towards PED Projects}

The Booklet includes 61 cases in 19 different countries in Europe (Table 1). Of the 61 projects, 29 projects, located in 13 European countries, declared a PED ambition while the rest of the projects (To-PED) are located in 14 European countries.

Table 1. Geographic distribution of projects.

\begin{tabular}{cccc}
\hline Country & & & \\
\hline Norway & 8 & 1 & $\mathbf{9}$ \\
Finland & 4 & 3 & $\mathbf{7}$ \\
Sweden & 1 & 5 & $\mathbf{6}$ \\
The Netherlands & 3 & 3 & $\mathbf{6}$ \\
Italy & 3 & 5 & $\mathbf{8}$ \\
Germany & 0 & 4 & $\mathbf{4}$ \\
Denmark & 0 & 2 & $\mathbf{2}$ \\
Austria & 2 & 2 & $\mathbf{4}$ \\
France & 1 & 1 & $\mathbf{2}$ \\
Spain & 2 & 2 & $\mathbf{4}$ \\
Switzerland & 0 & 1 & $\mathbf{1}$ \\
Romania & 1 & 0 & $\mathbf{1}$ \\
Estonia & 1 & 0 & $\mathbf{1}$ \\
Ireland & 1 & 0 & $\mathbf{1}$ \\
Belgium & 0 & 1 & $\mathbf{1}$ \\
Greece & 0 & 1 & $\mathbf{1}$ \\
Hungary & 0 & 1 & $\mathbf{1}$ \\
Turkey & 1 & 0 & $\mathbf{1}$ \\
Portugal & 1 & 0 & $\mathbf{1}$ \\
TOT & $\mathbf{2 9}$ & $\mathbf{3 2}$ & $\mathbf{6 1}$ \\
\hline
\end{tabular}

The highest number of projects of the Booklet (PED + To-PED) are located in Norway (9), Italy (8), Finland (7), Sweden (6), and The Netherlands (6).

In terms of PED projects, Norway contributed the most cases (8). On the contrary, only two PED/To-PED projects are located in Eastern and Southeastern Europe.

This geographical imbalance may be explained mainly with either of two factors: (1) policy priorities and implementation status of policies towards the energy transition vary between European countries; therefore, specific national programs on PEDs or PED-related matters have only been implemented in some countries. An example is represented by the ZEN Research Centre (https://fmezen.no/about-us/); nine pilot projects were spread over Norway with the aim of developing zero emission neighborhoods [10-12]. ZEN has public and industrial partners to guarantee a multidisciplinary approach that combines together researchers with building professionals, property developers, public authorities, energy companies, building owners, and users. (2) High support of national delegates for the PED Program in collecting information on PED projects in their countries.

\subsection{Implementation Status}

The template distributed to projects' representatives included a question related to the implementation status of their projects. Possible choices were: "Planned", "Implementation Stage", "Realized", "In Operation", and "n/a". Percentages of PED and Towards PED projects in different implementation phases are summarized in Figure 1. Most of PED projects (green) are in their implementation stage (69\%); $24 \%$ are in planning stage and only a minority are realized (3\%) or already in operation (3\%). To-PED projects (in blue) are mainly in their implementation stage (44\%), but also a 
considerable amount of them are already in operation (31\%); $9 \%$ are realized but not yet in operation. Only $13 \%$ of To-PED projects are in planning stage. As expected, PED projects are less mature than Towards PED projects; among them only one project is already in operation and only one is realized.

\section{IMPLEMENTATION STATUS for PED and TOWARDS PED PROJECTS}

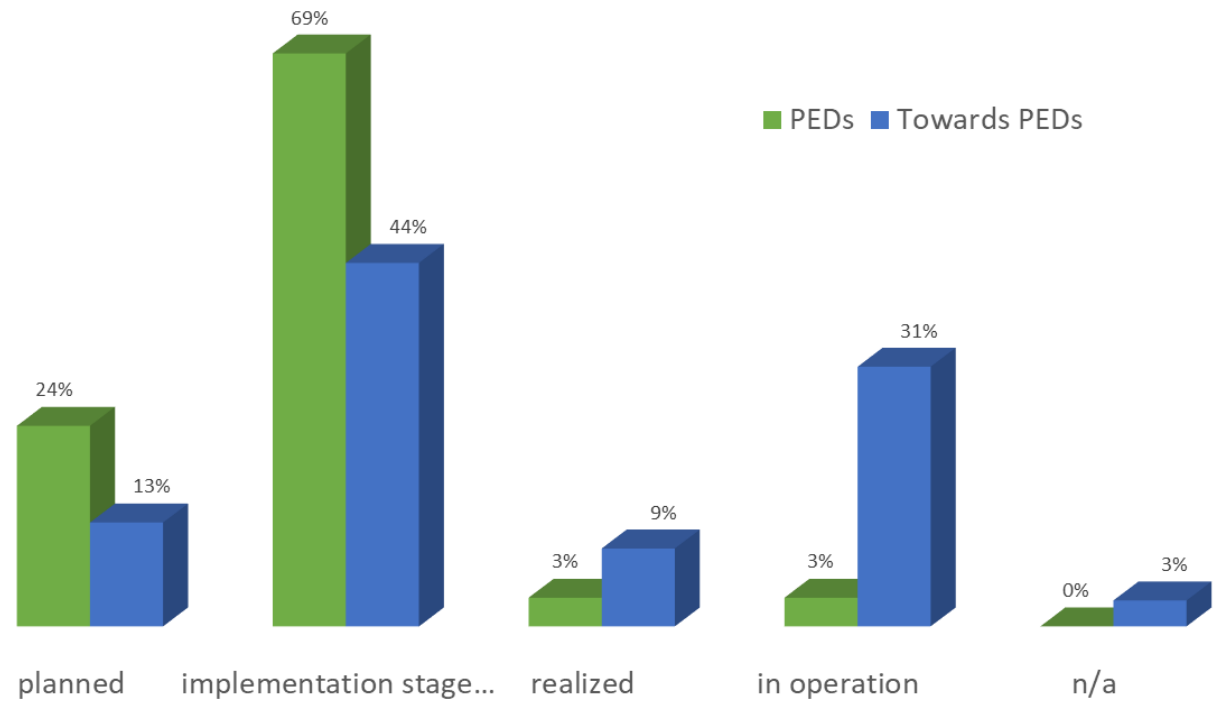

\begin{tabular}{|c|c|c|c|c|}
\hline \multirow[b]{2}{*}{ Project Status } & \multicolumn{2}{|c|}{ PED } & \multicolumn{2}{|c|}{ To- PED } \\
\hline & in Figures & in $\%$ & in Figures & in $\%$ \\
\hline planned & 7 & $24.14 \%$ & 4 & $12.50 \%$ \\
\hline implementation stage & 20 & $68.97 \%$ & 14 & $43.75 \%$ \\
\hline realized & 1 & $3.45 \%$ & 3 & $9.38 \%$ \\
\hline in operation & 1 & $3.45 \%$ & 10 & $31.25 \%$ \\
\hline Project status n/a & 0 & $0.00 \%$ & 1 & $3.13 \%$ \\
\hline
\end{tabular}

Figure 1. Implementation status of Positive Energy District and Neighborhood (PED) versus Toward (To)-PED.

\subsection{Building Structure}

Differences of projects' building structures were analyzed by dividing them into "Newly Built", "Existing Neighborhood" and "Mixed".

Projects with PED ambition mainly show a mixed typology (Figure 2); $66 \%$ of them combine newly built with existing neighborhoods, $28 \%$ of them are newly built districts, and only $7 \%$ are developed from existing neighborhoods. 


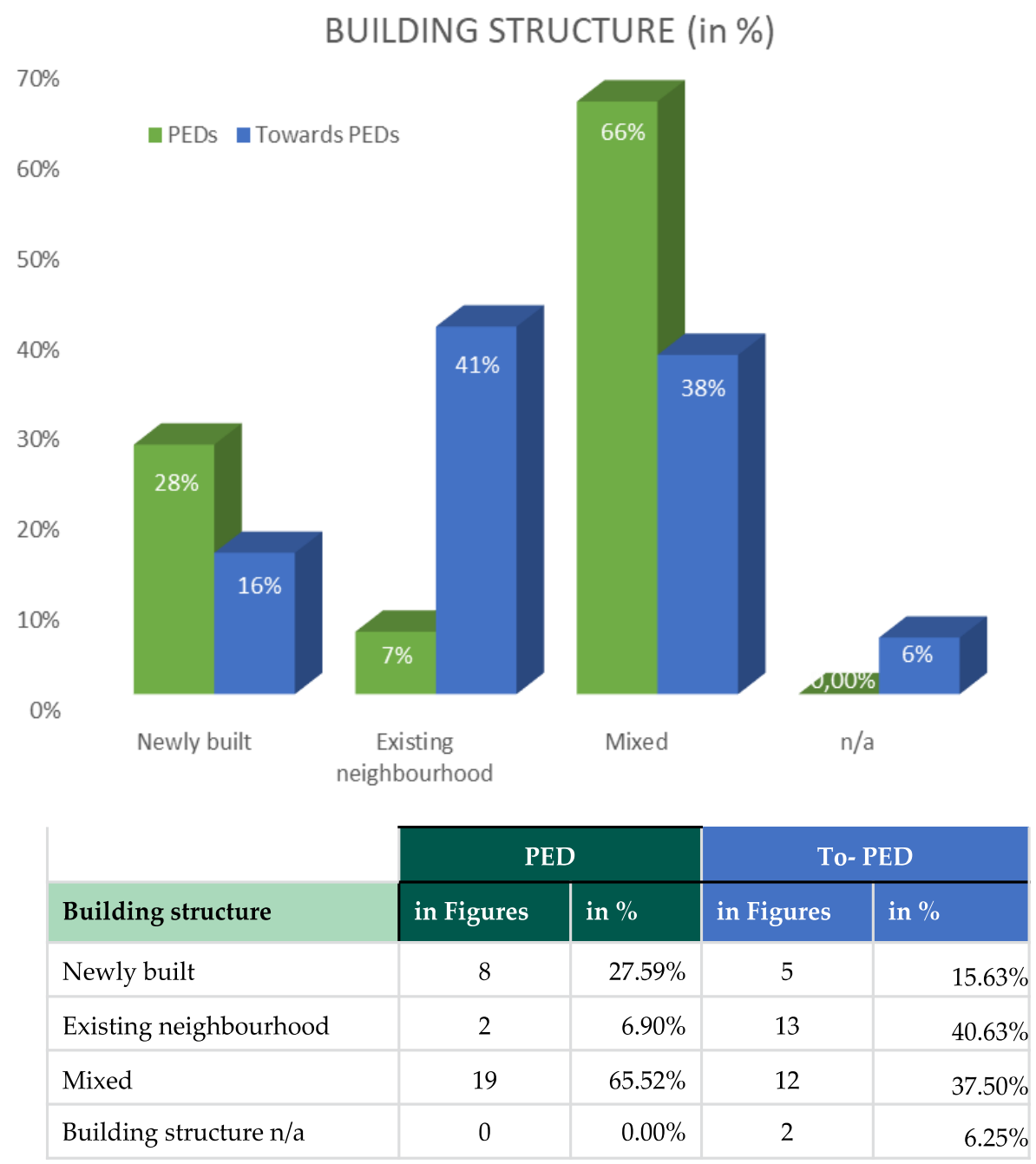

Figure 2. Building structure of PED versus To-PED.

On the contrary, To-PED projects are mainly based on existing neighborhoods $(41 \%)$. A considerable percentage of them is based on a mixed typology (38\%) and only $16 \%$ of Towards PED projects are newly built. A comparison among PED and Towards PED projects is shown in Figure 2.

PEDs results are in good agreement with the framework, which suggests the combination of new urban development areas with existing buildings.

\subsection{Land Use}

The Booklet includes information on land use of projects areas. Multiple choices were available for this topic: "Residential", "Office", "Industry", "Commercial", "Social", "Other", and "n/a".

Twenty-three PED and 17 To-PED projects specified a land use and results are summarized in Figure 3a. All the projects (100\% of PED and 100\% of To-PED) included residential use. In addition to residential use, $65 \%$ of PED projects included a social land use versus $29 \%$ of To-PED projects. Commercial activities were foreseen in $61 \%$ of PED and only in $24 \%$ of To-PED projects. More comparable percentages were observed for office spaces (61\% of PED versus $53 \%$ of To-PED) and industry (22\% of PED versus $18 \%$ of To-PED). In addition, $30 \%$ of PED and $47 \%$ of To-PED projects mentioned other typologies of land use (e.g., logistic hubs, natural facilities, waste water energy recovery systems, etc.). 


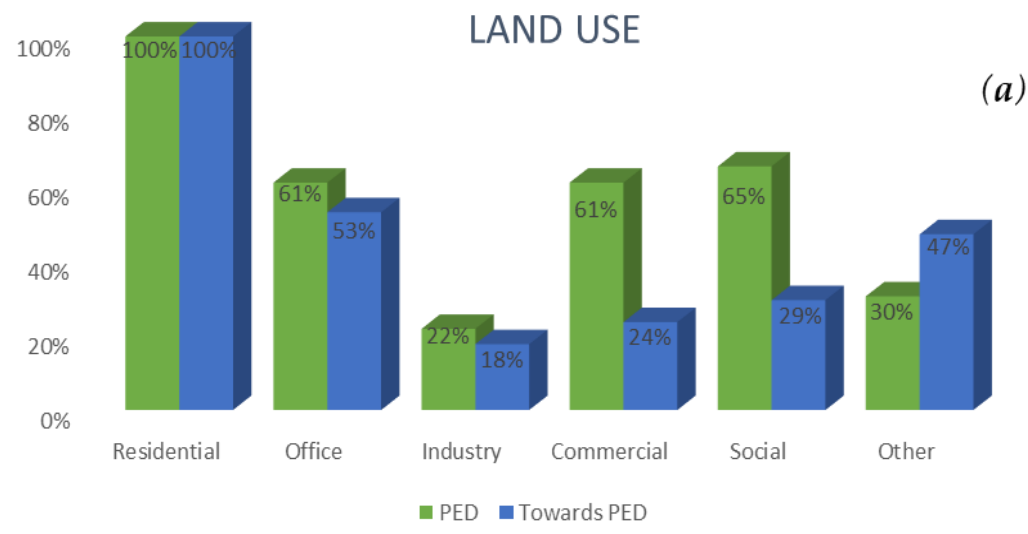

\begin{tabular}{|c|c|c|c|c|}
\hline \multirow[b]{2}{*}{ Land Use } & \multicolumn{2}{|c|}{ PED } & \multicolumn{2}{|c|}{ To- PED } \\
\hline & in Figures & in $\%$ & in Figures & in $\%$ \\
\hline Residential & 23 & $100.00 \%$ & 17 & $100.00 \%$ \\
\hline Office & 14 & $60.87 \%$ & 9 & $52.94 \%$ \\
\hline Industry & 5 & $21.74 \%$ & 3 & $17.65 \%$ \\
\hline Commercial & 14 & $60.87 \%$ & 4 & $23.53 \%$ \\
\hline Social & 15 & $65.22 \%$ & 5 & $29.41 \%$ \\
\hline $\begin{array}{l}\text { Other Land use (please } \\
\text { specify) }\end{array}$ & 7 & $30.43 \%$ & 8 & $47.06 \%$ \\
\hline Land Use selections & & & & \\
\hline single (1) & 1 & $4.35 \%$ & 1 & $5.88 \%$ \\
\hline moderate mixed (2-4) & 13 & $56.52 \%$ & 13 & $76.47 \%$ \\
\hline highly mixed (5+) & 9 & $39.13 \%$ & 3 & $17.65 \%$ \\
\hline
\end{tabular}

\section{LAND USE - Selections}

(b)

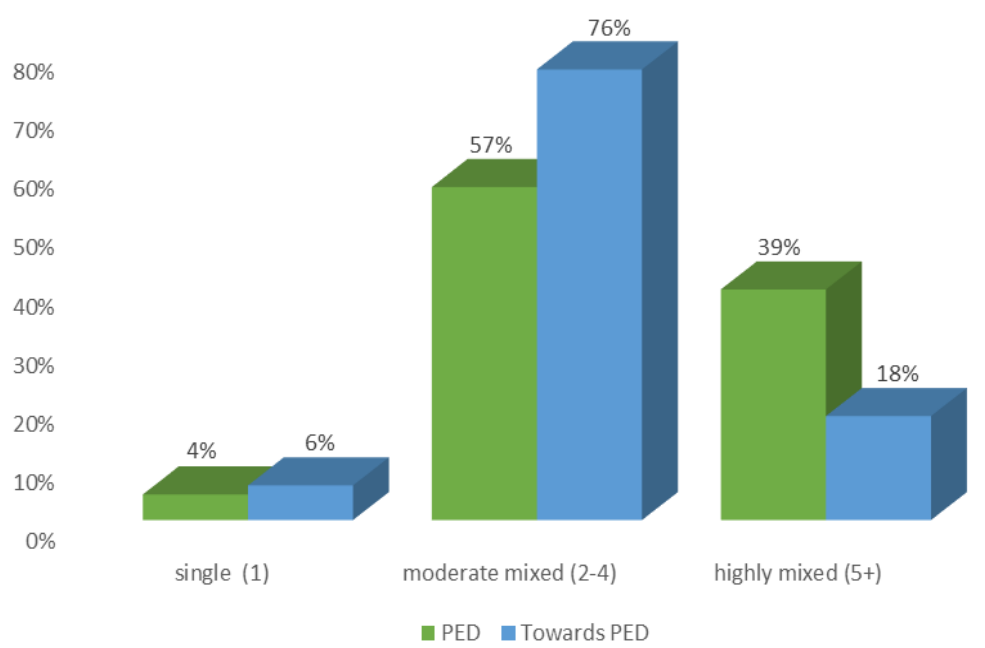

Figure 3. (a) Land use of PED versus To-PED; (b) land use selection of PEDs versus To-PED.

The number of different land use selections were counted for PED and Towards PED projects. The results reflect the degree of mixed use in the projects and were divided into three groups: "single use", "moderate mixed" (two to four land uses), and "highly mixed" (more than five land uses). Comparison results for PED and To-PED projects are summarized in Figure 3b. Only small percentages of PED and To-PED projects have a single land use. A high percentage of PED and To-PED projects have a moderate mixed land use, namely $57 \%$ and $76 \%$, respectively. A significant amount of PED projects has a highly mixed use (39\%), whereas the same is true in only $18 \%$ of Towards PED projects. 


\subsection{Energy Typology}

The template used so far included a question on "Typology of Energy Supply" where project representatives could select one or more of the following options: "Solar thermal energy", "Geothermal energy", "District heating/local heating", "Heat pump system", "Industrial waste heat", "Photovoltaic", "Other", and "n/a".

Answers to this question where collected for PED and To-PED projects and the results in percentage of total projects with energy data available are shown in Figure 4a. Most of the projects included "district/local heating" in their energy strategy, with similar percentages for PED (75\%) and To-PED projects (83\%). Several projects included "heat pump system", with $71 \%$ of PED and $60 \%$ of To-PED projects. Among PED projects, $71 \%$ of them exploited photovoltaic energy, while only $30 \%$ of To-PED projects used PV. The share of PV use represents the main difference between the two project categories, followed by the use of geothermal energy $-58 \%$ for PED versus $31 \%$ of To-PED. Half of PED use solar thermal energy versus $37 \%$ of To-PED; a similar result for PED and To-PED was observed for industrial waste heat (25\% and 33\%, respectively). Other typologies of energy supplies described by the PED projects included wind, biomass, waste digestion, and hydrothermal.

For each project, we evaluated the number of different typologies of energy supply combined together. Data obtained were classified in four different groups based on the number of energy sources used:

- $\quad$ Single (only one)

- Moderate mixed (two to three)

- Highly mixed (four to five)

- Very highly mixed (less than six)

The quantification of multiple energy sources integration for PED and To-PEDs is summarized in Figure $4 \mathrm{~b}$. Half of PED projects use "highly mixed" energy sources (4 or 5), 29\% are "moderate mixed", $13 \%$ are "very highly mixed", and only $8 \%$ use just a single source of energy.

Most of To-PED projects are "moderate mixed"; $60 \%$ use two or three sources of energy, $30 \%$ are "highly mixed", $7 \%$ use only a single source, and only $3 \%$ use "very highly mixed" energy typologies.

Results suggest that PEDs combine more energy sources (four or five) than Towards PED projects (two or three) to satisfy the energy surplus required. PED projects have the aim of reaching an energy surplus production from renewable energies. Combining a high number of energies is not the aim for a PED but it seems to be a frequent approach of PED projects. PED preferred energy typologies are district and local heating, heat pump systems, photovoltaic, and geothermal energy.

\subsection{Success Factors and Challenges of Projects Implementation}

An analysis of the statements regarding success factors and challenges/barriers of PED and To-PED projects (Figures 5 and 6) shows the perceived importance of stakeholder involvement. In fact, involvement processes (urban stakeholders, citizens) can be seen as defining elements for the success or failure of a project. Political support (or lack of it), most likely connected with funding, is seen as another key aspect, especially for PED. Capacity-building among decision-makers can thus be seen as a highly important task. Not only funding, but the elaboration of feasible business models also ranks very high among key aspects of PED development. 
(a)

ENERGY TYPOLOGY PED and TOWARDS PED
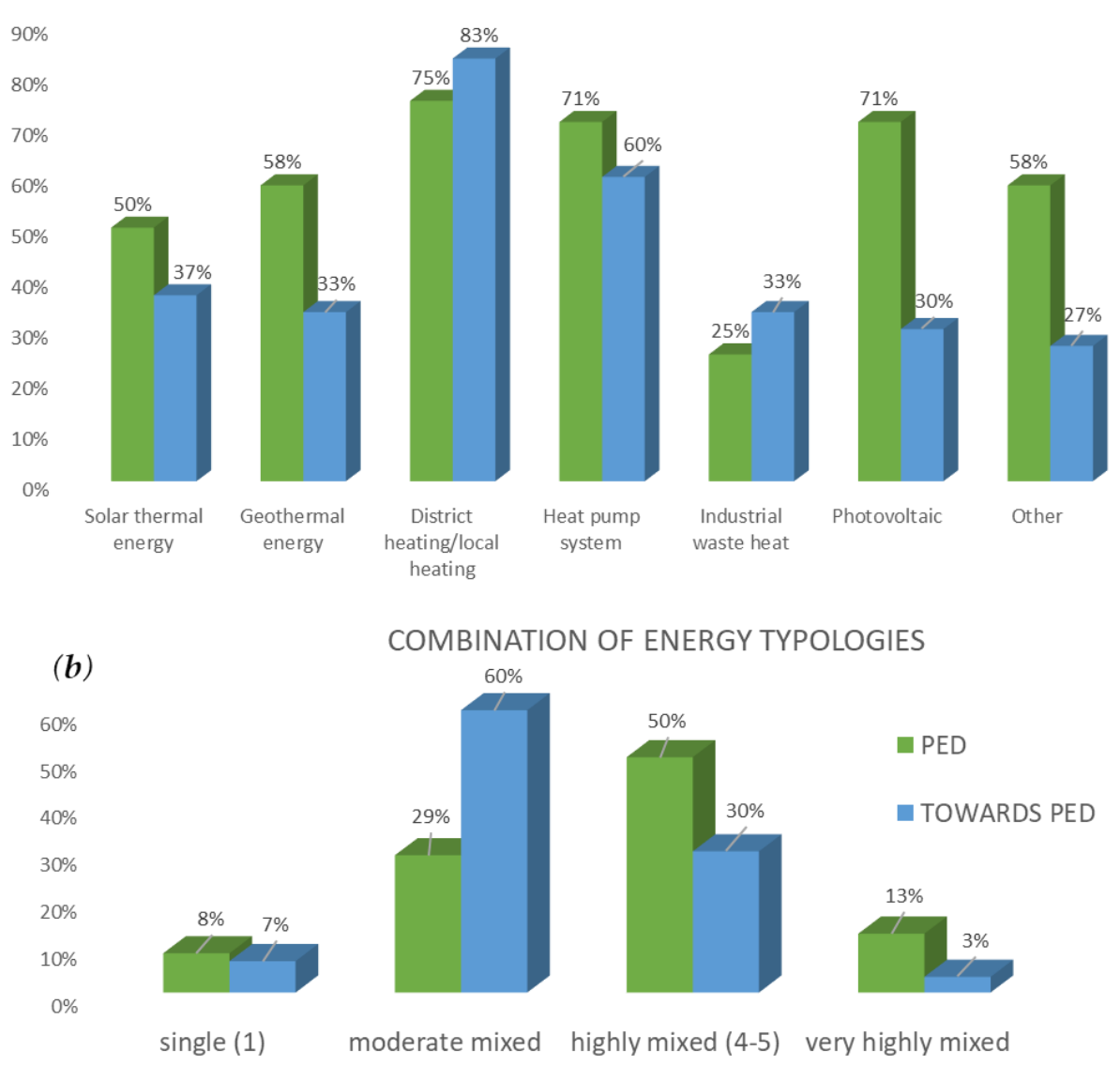

$(2-3)$

$(6+)$

\begin{tabular}{|c|c|c|c|c|}
\hline \multirow[b]{2}{*}{ Typology of energy supply } & \multicolumn{2}{|c|}{ PED } & \multicolumn{2}{|c|}{ To- PED } \\
\hline & in Figures & in $\%$ & in Figures & in $\%$ \\
\hline Solar thermal energy & 12 & $50.00 \%$ & 11 & $36.67 \%$ \\
\hline Geothermal energy & 14 & $58.33 \%$ & 10 & $33.33 \%$ \\
\hline District heating/local heating & 18 & $75.00 \%$ & 25 & $83.33 \%$ \\
\hline Heat pump system & 17 & $70.83 \%$ & 18 & $60,00 \%$ \\
\hline Industrial waste heat & 6 & $25.00 \%$ & 10 & $33.33 \%$ \\
\hline Photovoltaic & 17 & $70.83 \%$ & 9 & $30.00 \%$ \\
\hline Other & 14 & $58.33 \%$ & 8 & $26.67 \%$ \\
\hline \multicolumn{5}{|l|}{ Energy typology - selections } \\
\hline single (1) & 2 & $8.33 \%$ & 2 & $6.67 \%$ \\
\hline moderate mixed (2-3) & 7 & $29.17 \%$ & 18 & $60.00 \%$ \\
\hline highly mixed (4-5) & 12 & $50.00 \%$ & 9 & $30.00 \%$ \\
\hline very highly mixed (6+) & 3 & $12.50 \%$ & 1 & $3.33 \%$ \\
\hline
\end{tabular}

Figure 4. (a) Energy typology of PED versus To-PED; (b) energy typology selections of PED versus To-PED. 


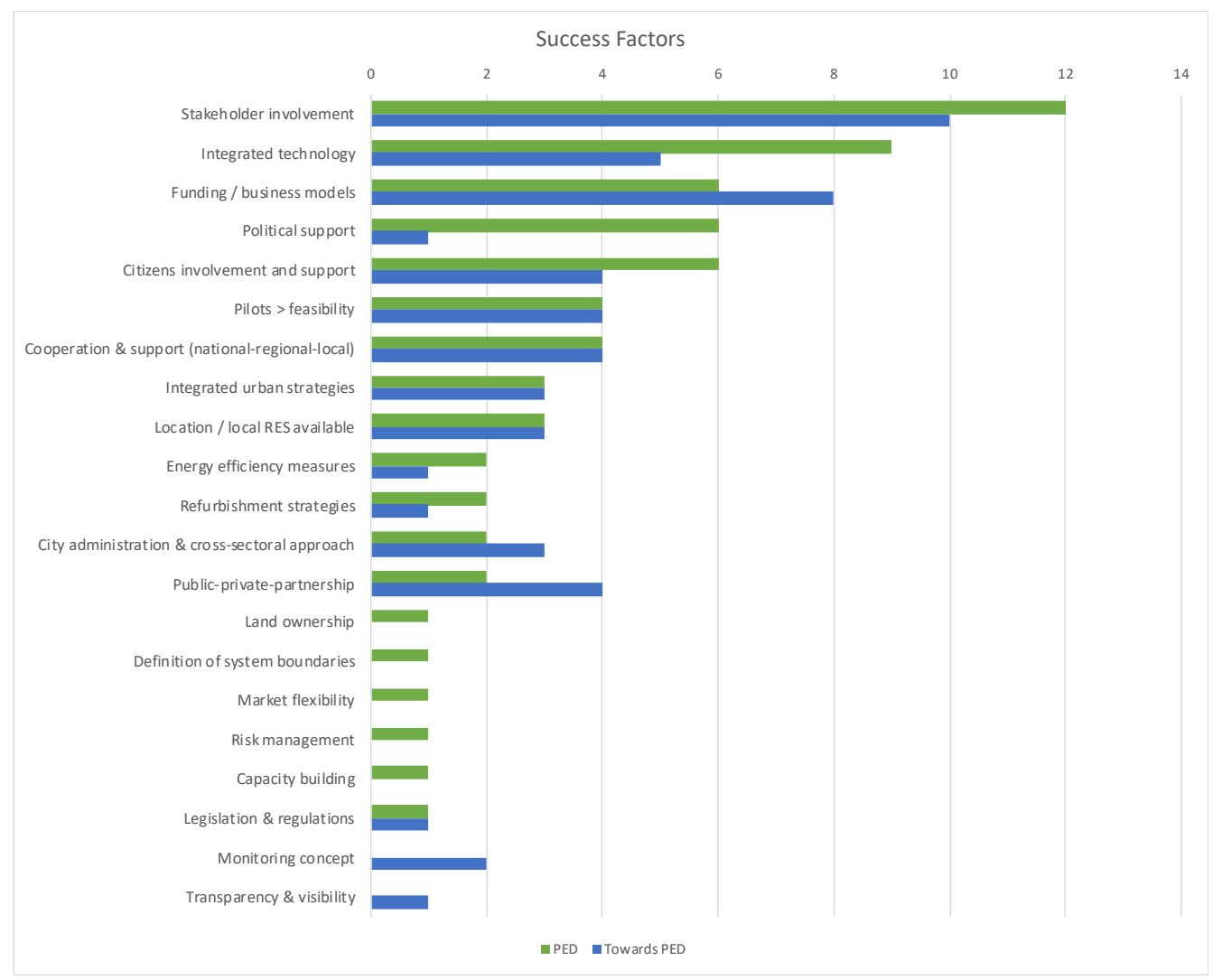

Figure 5. Success factors of implementation of PED and To-PED projects.

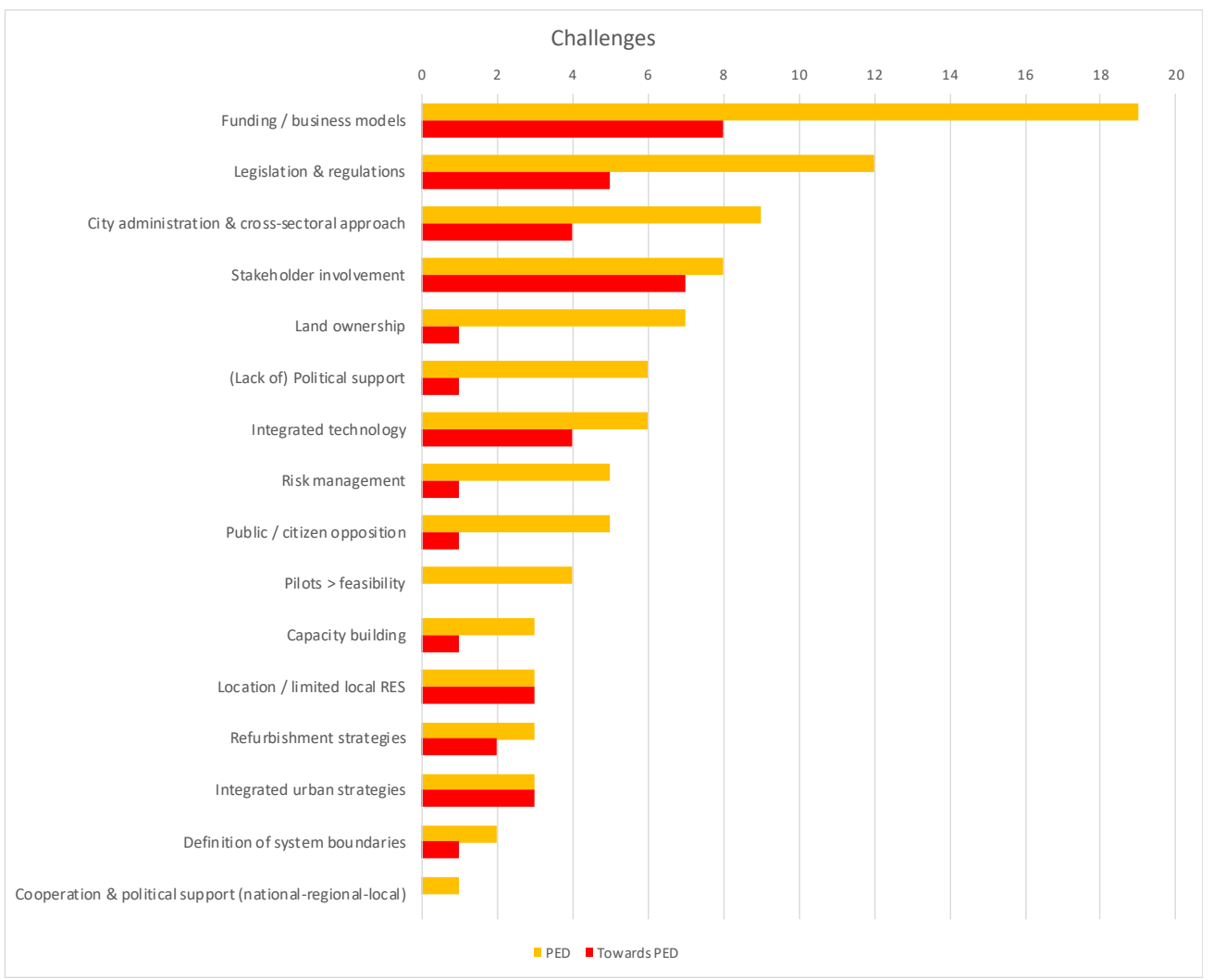

Figure 6. Challenges and barriers for implementation of PED and To-PED projects. 
A big challenge for successful implementation processes are legislation and regulations-an in-depth analysis of the particular legal barriers (on either local, national, or European levels) therefore seems to be highly relevant in particular for PED. Within the +CityxChange project, possible strategies to enable regulatory mechanisms have been studied [13].

\section{Discussion and Conclusions}

The analysis presented in this report was performed on data included in the first update of the PED Booklet (February 2020). The aim of this study is to evaluate trends, features, successes, or critical factors that contribute to development of PED projects in Europe.

There is a broad variety of projects addressing energy transition. While only 29 of 61 projects are planning to implement PEDs, all of them provide valuable approaches and strategies regarding actions towards the energy transition in the urban context. Most of the projects classified as Towards PEDs seem to include the possibility to develop into PEDs in a further step. However, the actual feasibility of many project designs is not yet assessable since a large share of the projects listed are in planning or early implementation stages. The PED Reference Framework, with its focus on energy functions and overall sustainability goals, provides an open framework-the results of the comparison between PED projects and Towards PEDs projects indicate that differences between the two groups are not categorical and the main issues and challenges of project implementation are similar. This therefore supports the assumption that projects with no self-declared PED ambition may be further developed to achieve PED status according to the PED Reference Framework. A further operationalization of the PED Reference Framework [5], which is currently under development, aims at a common PED definition that includes local differences and diverse approaches.

For this analysis it must be considered that not all countries have equally contributed to the Booklet yet. The Booklet is based on voluntary contributions from individual PED-related projects. Therefore, the results do not allow any interpretation about the level of PED efforts across Europe in general.

Nevertheless, these preliminary results highlight the importance of national programs and strong R\&I involvement in the replication of PED strategies, as for example in Norway where ZEN Research Center on Zero Emission and Neighborhoods in Smart Cities is helping the spreading of pilot projects in line with the PED framework. Future investigations on the impact of climatic zones on PED mainstreaming will be also considered.

Projects that declared a PED ambition are mainly in their planning or implementation stage (93\% versus $57 \%$ of To-PED). This suggests that most of PED strategies are still to be tested and optimized and a regular update of the Booklet cases and data analysis is needed. Efforts will continue to extend the data base, improve data quality, and assess these projects to identify good practice as well as critical issues at further stages.

Most projects with PED ambitions (66\%) combine newly built neighborhoods with existing neighborhoods. This result is in good agreement with the framework that suggests the combination of new urban development areas with existing buildings. Only 7\% of PED are developed in an existing neighborhood. The high complexity of a PED project requires deep interventions to fit with the new paradigm and might inhibit ambitions to apply PED ambitions to existing structures. The need for dealing with complex ownership structures or technological limitations, for instance regarding PV-instalment, in connection with other aspects of revitalization, for example, building protections and preservation of cityscape, are just two factors that need to be mentioned. Regarding the implementation of a PED ambition, it does not seem to be a common strategy to count only on existing neighborhood. However, for most European cities, transformation of the existing building stock is a key aspect for achieving the energy transition. Therefore, exploring, integrating and applying PED solutions and approaches to the existing urban structure seems to be a crucial challenge in the long run. An 8-step process to develop a PED is proposed by the JRC report [14]. 
A significant amount of PED projects involves a highly mixed land use (39\%) while only $18 \%$ of Towards PED projects do. Multifunctional urban structures can be seen as a basic requirement for successful PED implementation since they support efficient use of energy and more opportunities for energy flexibility. A high percentage of PED mentioned commercial and social use of the land. Multifunctionality is also a crucial requirement for embedding PED strategies in integrated urban planning strategies aiming at high quality of life and sustainable local development. This is in line with the framework definition that requires social and economic sustainability.

Another feature of PED is their highly mixed combination of energy typologies. Fifty percent of PED projects integrate four to five energy sources, whereas $60 \%$ of To-PED projects use two or three. This is a reasonable result given the fact that PED projects have the ambition to have an annual positive energy balance produced from renewable sources. To satisfy this ambitious aim, the combination of multiple energy typologies is key to exploit changing energies' availabilities, consumptions with different weather conditions, or with the alternation of day and night and seasons. Photovoltaics is used in 71\% of PED projects versus 30\% of To-PED projects. Photovoltaics is a mature and suitable technology for decentralized and renewable energy production. Its profitability is already reached in some European countries and increasing diffusion in building rooftop is expected [15]. This explains why a high percentage of PEDs rely on photovoltaics solar energy as local production of renewable energy.

Stakeholders, citizens involvement strategies, integrated technology, and political support are considered main success factors for PED development. A successful PED implementation requires collaboration with citizens and final users right from initial planning stages to avoid their opposition to the change of paradigm that a PED aims to do in terms of social, economic and energy sustainability. Political support is a necessary factor to activate national programs and new funding opportunities. Furthermore, the technical complexity of a PED is the reason why integrated technology was mentioned as a main feature to its success.

The main barrier for a PED is the access to adequate funding and business models (Figure 6). PEDs are more expensive than traditional projects and they require multiple sources of financing and advanced business models. Innovations and changes introduced by PED projects require ad hoc regulations and a dedicated legal framework. This explains why legislation and regulations, together with existing governance structures within city administrations and a lack of cross-sectoral approaches, are often mentioned as main reasons for inhibited implementation processes (Figure 6).

Considering the issues discussed, key areas of action to be further explored can be summarized as follows:

- Allowing for and testing of a diversity of approaches and strategies: exploring room for experimenting with and implementing of PED Labs; monitoring existing approaches the and elaboration of guides and tools

- Developing fitting governance structures and the legal framework: consideration of Functional Urban Areas (regional perspective); inter-departmental cooperation within city administrations and collaboration between city administrations, energy providers, real estate industry, civic society, and other stakeholders; re-consideration and adaptation of legislation and regulations

- Integration of PED strategies in holistic urban planning: mainstreaming of energy planning in urban planning strategies; connecting energy aspects with climate action; a high quality regard for functions and design

- Developing feasible business models and funding opportunities: creating awareness and political support for development and implementation of national programs; consideration of different settings (especially the availability of renewable energy sources) and technological solutions; exploring job creation and boosting local/regional economy

- Exploration of strategies in existing urban structures: combining revitalization and greening strategies; involving stakeholders with a special focus on landowner and citizen participation 
Based on these preliminary observations, the next activities will focus on the following aspects:

- Integration of key findings into PED Program activities

- Developing the PED Booklet as strategic tool for the PED Program

- $\quad$ Updating the template to collect project descriptions

- $\quad$ Updating the PED Booklet with more cases across Europe

Author Contributions: Conceptualization: C.G. and S.B.; methodology: S.B. and C.G.; software: S.B., S.T., and C.G.; validation: S.B. and C.G.; formal analysis: S.B. and C.G.; investigation: S.B. and C.G.; resources, S.B. and C.G.; data curation, S.B. and S.T.; writing—original draft preparation, S.B.; writing—review and editing, C.G.; visualization, S.B.; supervision, C.G.; project administration, C.G.; funding acquisition, C.G. All authors have read and agreed to the published version of the manuscript.

Funding: This research received no external funding.

Acknowledgments: The authors would like to thank all project representatives who provided data on the projects presented in the PED Booklet, which served as basis for this analysis. Furthermore, the authors would also like to acknowledge the support of SET Plan Action 3.2 Italian National Delegate Paola Clerici and the work of the PED Program Management, specifically Margit Noll, Hans-Günther Schwarz, Robert Hinterberger, and Susanne Meyer, and the contributions of the PED Program Stakeholders Group, specifically EERA JPSC, regarding overall conceptualization of the PED Program and the elaboration of the PED Framework, which is a fundamental basis for the analysis of the data provided.

Conflicts of Interest: The authors declare no conflict of interest.

\section{References}

1. Pichler, P.P.; Zwickel, T.; Chavez, A.; Kretschmer, T.; Seddon, J.; Weisz, H. Reducing Urban Greenhouse Gas Footprints. Sci. Rep. 2017, 7, 14659. [CrossRef] [PubMed]

2. Sustainable Development Goal 11: Make Cities and Human Settlements Inclusive, Safe, Resilient and Sustainable. Available online: https://sustainabledevelopment.un.org/sdg11 (accessed on 5 June 2019).

3. SET-Plan Action 3.2 on Smart Cities and Communities. Available online: https://setis.ec.europa.eu/system/ files/setplan_smartcities_implementationplan.pdf (accessed on 12 October 2020).

4. JPI Urban Europe, Positive Energy Districts (PED). Available online: https://jpi-urbaneurope.eu/ped/ (accessed on 12 October 2020).

5. Framework Definition for Positive Energy Districts and Neighbourhoods. March 2020. Available online: https://jpi-urbaneurope.eu/app/uploads/2020/04/White-Paper-PED-Framework-Definition-2020323final.pdf (accessed on 12 October 2020).

6. Alpagut, B.; Akyürek, Ö.; Mitre, E.M. Positive Energy Districts Methodology and Its Replication Potential. Proceedings 2019, 20, 8. [CrossRef]

7. Ahlers, D.; Driscoll, P.; Wibe, H.; Wyckmans, A. Co-Creation of Positive Energy Blocks, 1st Nordic conference on Zero Emission and Plus Energy Buildings. Earth Environ. Sci. 2019, 352, 012060.

8. Magrini, A.; Lentini, G.; Cuman, S.; Bodrato, A.; Marenco, L. From nearly zero energy buildings (NZEB) to positive energy buildings (PEB): The next challenge-The most recent European trends with some notes on the energy analysis of a forerunner PEB example. Dev. Built Environ. 2020, 3, 100019. [CrossRef]

9. Europe towards Positive Energy Districts, First Update. Available online: https:/jpi-urbaneurope.eu/app/ uploads/2020/03/PED-Booklet-Update-Feb2020_.pdf (accessed on 1 October 2020).

10. Berker, T.; Woods, R. Identifying and addressing reverse salients in infrastructural change. The case of a small zero emission campus in Southern Norway. Int. J. Sustain. High. Educ. 2020, 21. [CrossRef]

11. Cachat, E.T.; Grynning, S.; Thomsen, J.; Selkowitz, S. Responsive building envelope concepts in zero emission neighborhoods and smart cities-A roadmap to implementation. Build. Environ. 2019, 149, 446-457. [CrossRef]

12. Backe, S.; Kvellheim, A.K. Zero Emission Neighborhoods—Drivers and Barriers towards Future Development; ZEN Report 22; NTNU/SINTEF: ZEN, Norway, 2020.

13. Bertelsen, S.; Livik, K.; Myrstad, M. D2.1 Report on Enabling Regulatory Mechanism to Trial Innovation in Cities. +CityxChange, Work Package 2, Task 2.1; +Cityxchange, H2020, Grant Agreement No. 824260. Final delivery date: 31 July 2019.

14. Shnapp, S.; Paci, D.; Bertoldi, P. Enabling Positive Energy Districts across Europe: Energy Efficiency Couples Renewable Energy; JRC Technical Report; Publications Office of the European Union: Luxemburg, 2020. 
15. Vimpari, J.; Seppo, J. Estimating the diffusion of rooftop PVs: A real estate economics perspective. Energy 2019, 172, 1087-1097. [CrossRef]

Publisher's Note: MDPI stays neutral with regard to jurisdictional claims in published maps and institutional affiliations.

(C) 2020 by the authors. Licensee MDPI, Basel, Switzerland. This article is an open access article distributed under the terms and conditions of the Creative Commons Attribution (CC BY) license (http://creativecommons.org/licenses/by/4.0/). 